\title{
A comparison of the views of nursing students and clinical educators on students' ethical sensitivity
}

Soheyla Kalantari ${ }^{1}$, Leila Jouybari², Akram Sanagoo ${ }^{2}$, Mitra Hekamt Afshar $^{3}$, Esmat Nouhi ${ }^{4}$

\author{
Journal of Research \& Health \\ Social Development \& Health Promotion \\ Research Center \\ Vol. 7, No. 1, Jan \& Feb 2017 \\ Pages: 647- 652. \\ DOI: 10.18869/acadpub.jrh.7.1.647 \\ Original Article
}

1. Department of Operation Room, School of Paramedical, Golestan University of Medical Sciences, Gorgan, Iran

2. Department of Nursing, Faculty of Nursing, Golestan University of Medical Sciences, Gorgan, Iran

3. Correspondence to: Department of Nursing and Midwifery, Faculty of Nursing ,Shahid Beheshti University of Medical Sciences, Tehran, Iran

Email: m.hekmatafshar@yahoo.com

4. Department of Nursing, Faculty of Nursing, Kerman University of Medical Sciences, Kerman, Iran

Received: 26 Sep 2013 Accepted: 18 Mey 2015

How to cite this article: Kalantari S, Jouybari L, Sanagoo A, Hekamt Afshar M, Nouhi E. A comparison of the views of nursing students and clinical educators on students' ethical sensitivity. J Research \& Health2017; 7(1): 647- 652.

\begin{abstract}
Health professionals frequently confront serious situations in which an ethical judgment is required clinical practice. Based thinking of nurses to respect the life, times, and human rights. This means that nurses have the moral and legal rights of patients to recognize and protect these rights are responsible. Despite the importance of moral sensitivity in nursing students, the purpose of this study was to assess the ethical sensitivity of nursing students and compare their views and their teachers about the ethical sensitivity of students. In this study using convince sampling 42 nursing students and 12 nursing clinical instructors from Golestan University of Medical Sciences, participated. The data collected reliable and valid moral sensitivity questionnaire. The mean age of students and teachers were 22.59 and 42.66 respectively. The mean of moral sensitivity score by self evaluation was $56.64 \pm 9.2$ and by teacher assessment was $51.17 \pm 13.2$. The students selfevaluation scores for some questions such as patient's rights, ethical dealing with difficult circumstances, and using previous experiences, were better than the teacher's assessment, however the statistics showed no significant relationship between the scores of moral sensitivity of these two groups. The results showed the students' perceptions of their ethical sensitivity compared to teachers about their views were not significantly different. This could indicate a true understanding of nursing instructors from moral sensitivity of their students.
\end{abstract}

Keywords: Educator, Ethical, Nursing, Sensitivity, Student

\section{Introduction}

Ethics and ethical considerations have always been an integral part of patient care in all its physical, mental and spiritual dimensions. Nursing has traditionally been considered an ethical profession due to its care obligations; however, recently, moral and legal issues in nursing have become more important than ever in different societies due to the increasing advances in technology and medical and pharmaceutical equipment, resource allocation problems, the rising costs and the aging population $[1,2]$. Many nurses observe professional ethics in dealing with ethical dilemmas in clinical practice; however, they do not seek solutions to these dilemmas. According to Hassanpour, some studies have shown that Iranian nurses do not properly consider ethical principles in making decisions and are not ethically 
sensitive to certain situations [3].

Ethical sensitivity enables people to recognize ethical conflicts, develop a sensory and intellectual understanding of vulnerable situations and know about the ethical outcomes of making decisions about others [4]. Lutz et al. describe ethical sensitivity as a predetermined moral decision made by the individual that maybe formed by the emotional response to an ethical practice [5].

Studies show that ethics training and application are influential in the workplace and ethical decision-making skills are better in students who have taken classes on ethical and moral issues compared to those who have not [6]. A study conducted in Korea in 2014 reported the ethical sensitivity score of nursing students as 2.83 out of 7 , suggest in galow ethical sensitivity in clinical practice [7]. Another study in Iran reported the score of ethical sensitivity in senior nursing student's as 4.77 [8]. Quoting Mattick and Yousefi writes that $57 \%$ of medical faculty members in the UK consider the gradual learning and understanding of medical ethics appropriate for medical students and believe that clinical programs should incorporate medical ethics into their curricula [9]. The results of another study on ethics education showed that ,as they ears spent at the university increase, the student's capacity for ethical reasoning in sensitive situations also improves [10]. Training programs can thus help improve ethical practice in clinical settings among nursing students [11]. It is evidently the nurse's job to solve the conflict between her decisions, her profession and the patients' values by making appropriate decisions [12]. Improving ethical sensitivity creates a fundamental attitude and reaction in nurses that enables them to provide effective ethical care to their patients [4]. It is therefore crucial for professional nurses to be ethically sensitive, to understand ethical issues and to think analytically [13]. Since the school years provide the perfect opportunity for developing ethical sensitivity in nursing students, it is crucial for the education authorities to address this issue [14]. Nursing students become familiarized with different models of ethical decision-making during their years of nursing education to then find tensions between what they have learn and how the actual clinical conditions are after they graduate, and then have to demonstrate their clinical competence and ethical sensitivity in the workplace [8]. Having ethical sensitivity in clinical settings is therefore crucial for nursing students entering the workforce in the future. Since clinical educators are in close touch both with clinical issues and students [15], they can evaluate the students' ethical performance in clinical settings; nevertheless, the researcher did not manage to find any studies in which nursing students' ethical sensitivity was assessed by their clinical educators. The present study was the refor conducted to evaluate and compare nursing students' ethical sensitivity from their own perspective and from the perspective of their teachers.

\section{Method}

The present cross-sectional study examined ethical sensitivity among nursing students at Golestan university of medical sciences, the North of Iran, in 2011 and compared the student's own views about their ethical sensitivity with the views of their clinical educators. The participants were selected through census sampling and comprised of 42 senior nursing students and 12 clinical nurse educators. The study inclusion criteria for the clinical educators consisted of having at least two years of experience as clinical nurse educator.

The data collection tools used included the ethical sensitivity questionnaire consisting of two parts; first, a demographic detail section (age, gender, marital status, history of participation in ethics workshops, etc.), and second, a part with 25 items on the students' ethical sensitivity. This questionnaire included items about sensitive situations requiring ethical decision-making. To determine the students' ethical sensitivity, a five-point Likert scale was used with options including strongly agree, somewhat agree, somewhat disagree, strongly disagree and neutral and the highest and lowest scores given were 100 and 25 . 
Obtaining a score of 25-50 on the questionnaire indicated low ethical sensitivity, a score of 50-70 indicated moderate and a scoreabove75 indicated high ethical sensitivity.

This questionnaire was extracted from a study conducted in 2010 in Korea on ethical sensitivity in nurses [16]. The questionnaire was first translated by the researcher and then translated back into English by an expert in the English language. The English text was then revised by experts and the accuracy of the translation was approved. Some changes were then made to the questionnaire for it to be able to assess the ethical sensitivity of students. The content validity of the questionnaire was confirmed by number of faculty members. To examine its reliability, a pilot study was conducted and the internal consistency of the questionnaire was determined and the validity coefficient of the entire questionnaire was then obtained through measuring its Cronbach's alpha (88\%). To collect data, the researchers first obtained ethical permission from the Student Research Committee and then visited the hospitals in which the students were training. They then explained the study objectives and the methods of data collection and presentation and ensured the participants about the confidentiality of their personal information and the anonymity of the questionnaires and any other ethical issues that needed to be discussed. After the participants gave their consent for participation in the study, the researchers gave them the questionnaire to fill out and submit.

The statistical analysis of the data was carried out in SPSS-11 using descriptive and inferential statistics. The relationship between the students' self-assessment scores and their teachers' views about their ethical sensitivity was measured through the independent t-test and Pearson's correlation test. The level of statistical significance was at $\mathrm{p}<0.05$.

\section{Results}

A total of 54 participants entered the study, consisting of 42 students and 12 educators, $55.6 \%$ of which were female and $44.4 \%$ male. The mean age of the students was 22.59 with the standard deviation (SD) of 1.30, ranging from a minimum of 20 to a maximum of 26. The mean age of the teachers was 42.66 . The results showed that $55.6 \%$ of the students had never participated in ethics workshops.

The analysis of the data showed that the mean and standard deviation of the students' ethical sensitivity was $56.64 \pm 9.2$ from the students' own perspective and $51.17 \pm 13.2$ from their teachers' perspective (Table 1).

Table 1 The mean score of the students' ethical sensitivity from their own and their teachers' perspectives

\begin{tabular}{lc}
\hline Ethical sensitivity & Mean (Standard Deviation) \\
\hline Educators' perspective & $51.17( \pm 13.2)$ \\
Students' perspective & $56.64( \pm 9.2)$ \\
\hline
\end{tabular}

There were no significant differences between the students' self-assessment scores and their teachers' views about their ethical sensitivity $(\mathrm{p}=0.073)$.

Nevertheless, there were significant differences in some of the items on clinical ethical conflicts between the students' self-assessment scores and their teachers' evaluation. Overall, 52.9\% $(\mathrm{SD}= \pm 0.34)$ of the students chose the "strongly agree" option in response to the item on ethical sensitivity in dealing with difficult situations and making ethically correct decisions, while their teachers chose the "strongly agree" option in only $47.1 \%(\mathrm{SD}= \pm 0.07)$ of the cases, making for a significant difference between the students' self-assessment of their ethical sensitivity and their teachers' evaluation with regard to this item $(\mathrm{p}=0.023)$.

A total of $69 \%$ of the students $(S D= \pm 1.21)$ believed that they respected the patients' rights in making ethical decisions, while only $31 \%$ $(\mathrm{SD}= \pm 0.09)$ of the educators believed in such level of respect in the students. However, no significant differences were observed between the students' self-assessment and their teachers' evaluation with regard to this item 
$(\mathrm{p}=0.222)$.

Consulting with others when faced with difficult situations requiring ethical sensitivity was another item on which the students evaluated themselves higherthan did their teachers $(81.5 \pm 1.04 \%$ vs $18.5 \pm 0.02)$ and the difference was statistically significant with respect to this item $(\mathrm{p}=0.01)$.

The results also showed that students are often faced with situations in which it is difficult to allow the patients to make their own decisions about their problem, and a significant difference was also observed between the students' selfassessment and their teachers' evaluation with regard to this item $(\mathrm{p}=0.01)$.

The Pearson correlation test revealed no relationships between age and ethical sensitivity and its components among the students. In addition, the students' overall score of ethical sensitivity did not differ significantly by gender.

\section{Discussion}

The students' self-assessment score of ethical sensitivity was 56.64 in this study, while their teachers gave them a final score of 51.17. This difference in scores is more likely attributed to the inadequate presence of educators in hospitals and clinical settings for observing the students. This inadequate presence impedes their understanding of the students' ethical sensitivity. The limited research focused on clinical educators and their role in teaching ethical issues and ethical decision-making in sensitive cases may imply the little emphasis placed by the education system on the role and effect of clinical educators as ethics teachers [17]. A study conducted by Larijani to introduce 500 ethical issues and dilemmas to students as part of their medical ethics training showed that teachers should teach their students how to properly deal with different ethical problems as part of their curricula and emphasize subjects such as honesty, end of life, medical mal practice and the proper way of transferring patients from one care provider to another [18].

The findings of the study also revealed gap between the educators' and the students' views about understanding the importance of decision- making in difficult situations, which may reflect the quality of the programs and the current education system. The results of one study suggest that the different values and criteria held by the educators and the students comprise one of the major problems in the evaluation of clinical education [19]. The study by Larijani and Motevasely [18] on new methods of medical education showed that more exposure to ethical problems makes the students more inclined to learn about ethical approaches to communication with patients. Teachers and planners of medical ethics recommend that more appropriate and inclusive training programs be developed for physicians to learn about ethical problems and proper ethical decision-making. The researchers also emphasized the importance of designing interdisciplinary training with the cooperation of both medical ethics experts and moral philosophy professors [18]. In one study, Holm et al. examined the effect of training on students' moral understanding and showed that the students reached a higher level of moral reasoning and a better understanding of ethical problemsafter passing courses in medical ethics [20].

Students graduate with specific beliefs and behaviors, but end up hearing things in the clinical setting that diminish their ethical sensitivity to a degree and makeethical decisionmaking difficult for them [18]; reaching a more reliable conclusion on this issue requires more exclusive studies on teaching ethics for clinical practice, particularly on the students' ethical sensitivity and their teachers' evaluation of it. The findings of this study showed only $47 \%$ of the students to be ethically sensitive to their patients' rights; however, their teachers believed that $75 \%$ of them were sensitive to such issues. The difference between the students' self-assessment and their teachers' evaluation of their ethical sensitivity can be attributed to their training [20]. Nursing students are faced with various learning opportunities during their years of education, and ethical decision-making with respect to the patients' rights is an integral part of these 
opportunities. In addition to considering their own learning needs, students should also respect the rights of their patients [17].

The results of the present study showed that nursing students' previous experience of difficult situations does not affect their ethical sensitivity. This finding may be attributed to the education system's lack of attention to this area of training; that is, the student has faced several difficult situations, but has never received any training on how to deal with them.

The limitations of this study include the small sample size, especially with regard to the number of educators. More robust results can be obtained by conducting similar studies with larger sample sizes.

Given the importance of ethics and ethical sensitivity in clinical practice and teaching nursing ethics, the researchers recommend that ethics training be incorporated into nursing curricula. Moreover, ethical codes and relevant concepts and issues, including ethical decisionmaking, ethical dilemmas and ethical distress, should comprise the main subjects taught in ethics courses, and difficult ethical cases and sensitive scenarios should also be described to students in clinical training with an attention to proper ethical decision-making.

Further intervention studies are recommended to be conducted on clinical ethics for nursing students as well as clinical educators.

\section{Conclusion}

Clinical training is comprised of activities that facilitate learning in a clinical setting in which the educator and the student are equally involved and that aim to create tangible changes in the students' performance of professional clinical care [21]. Students can be trained to recognize ethical dilemmas through different teaching techniques, such as role-play, critical thinking and problem-solving based learning, and thus grow sensitive to ethical issues and select the best and most ethical patient care solution when faced with these dilemmas.

\section{Acknowledgements}

The authors would like to express their gratitude to all the teachers and students of Bouyeh Faculty of Nursing and Midwifery, Golestan University of Medical Sciences, for their cooperation and assistance, as well as the Nursing Research Center of the university.

\section{Contribution}

Study desing: SK, MHA

Data collection and analysis: AS, EN

Manuscript preparation: LJ, SK, MHA

\section{Funding}

The author (s) received no financial support forthe research, authorship and/or publication of this article.

\section{References}

1- Cronqvist A, Theorell T, Burns T, Lützén K. Caring about-caring for: moral obligations and work responsibilities in intensive care nursing. Nurs Ethics2004; 11(1): 63-76.

2- Schluter J, Winch S, Holzhauser K, Henderson A. Nurses' moral sensitivityand hospital ethical climate: a literaturereview. Nurs Ethics2008; 15(3): 304-21.

3- Hassanpour M, Hosseini MA, Fallahi M, Abbaszadeh A. Evaluation of the Impact of Teaching Nursing Ethics on Nurses' Decision Making in Social Security Hospitals of Kerman Province in 1389. Journal of Medical Ethics and History of Medicine2011; 4(5): 58-64.

4- Izadi A, Imani H, Khademi Z, Fari Asadi Noughabi F, Hajizadeh N, Naghizadeh F. Moral sensitivity of critical care nurses in clinical decision making and its correlation with their caring behavior in teaching hospitals of Bandar Abbas in 2012. Iranian Journal of Medical Ethics and History2013; 6(2):43_56.

5- Lutze K, Blom T, Ewalds-Kvist B, Winch S. Moral stress, moral climate and moral sensitivity among psychiatric professionals. Nurs Ethics2010; 17(2): 213-24.

6- Borhani F, Alhani F, Mohammadi E, Abbaszade A. Development of nursing professional ethics competence, necessity and challenges in ethic education. Journal of Medical Ethics and History of Medicine2009; 2(3): 2738.

7- Ahn SH, Yeom HA. Moral sensitivity and critical thinking disposition of nursing students in Korea. Int $J$ Nurs Pract2014; 20(5): 482-9.

8- Aabaszadeh A, Borhani F, Moazennematolahi L . The comparison of the level of moral sensitivity in nursing student and nurses of kerman university of medical science. Medical Ethics Journal2010; 4(12): 39-54. 9.Yosefi M, Ghanbar M, Mohagheghi M, EmamiRazavi 
S. The Possibility of Including Medical Ethics Courses in the Clinical Training of Medicine Students: Academic Members' Viewpoints. Journal of Strides in Development of Medical Education2012; 9(1): 1-10.

10- Borhani F, Abbaszadeh A, Kohan M, Fzail M. Comparison of moral reasoning ability of nurses and nursing students, Kerman University of Medical Sciences in dealing with ethical problems. Journal of Medical Ethics and History2010; 3(4): 71-81.

11- Lützén K, Evertzon M, Nordin C. Moral sensitivity in psychiatric practice. Nurs Ethics1997; 4: 472-82.

12- Abbaszadeh A, Borhani F, Kalantary S. Moral distress of nurses in Bam health centers. Medical Ethics Journal2011; 5(11): 119-140.

13- Kim S, Park J, Seo HS. Sensitivity to ethical issues confronted by Korean hospital staff nurses. Nurs Ethics2005; 12(6) :595-60.

14- Borhani F, Abbaszade A, Mohsenpour M. Nursing students' perceived of barriers to professional ethics sensitivity: a qualitative study. $J$ Med Ethics Hist Med2001; 5(16): 84-104.

15- Zamanzadeh V, Abdollahzadeh F, Lotfi M, Aghazadeh A. Assessing Clinical Education Fields from the Viewpoints of Nursing and Midwifery Instructors in Tabriz University of Medical Sciences, 2006. Iranian Journal of Medical Education2008; 7(2): 299-306.

16- Han SS, Kim J, Kim YS, Ahn S. Validation of a Korean version of the Moral Sensitivity Questionnaire. Nurs Ethics2010; 17(1): 99-105.

17- Azimi A, Alhani F. Educational challenges in ethical decision making in nursing. Journal of Medical Ethics and History2008; 1(4): 21-30.

18- Larijani B, Motevaseli E. New methodes of medical ethics education. Iranian Journal of Diabetes and Metabolism2005; 4: 39-46.

19- Unruh JA, Topeka KS. Moral distress: a living nightmare. J Emerg Nurs2010; 36(3):253-5.

20- Ghanbari A, Khaleghdoost R. Compared the views of nurses and nurse educators about the extent of the patient's rights. Journal of Nursing Studies2006; 1(1): 35-40.

21- Abbaszade A, Borhani F, Sabzevari S. Nursing teachers' perception of the challenges of clinical education and solutions: A qualitative study. Journal of Qualitative Research in Health Sciences2013; 2(2) :134-45. 